\title{
Sintesis Biodiesel dari Minyak Jelantah Menggunakan Katalis Bentonit, K-Bentonit Dan K-Bentonit Terimpregnasi $\mathrm{CaO}$
}

\author{
Hasmalina Nasution ${ }^{1}$, Wahyuni Puspita Sanda ${ }^{1}$, Rahmadini Syafri ${ }^{1}$, Sri Hilma Siregar ${ }^{1}$, \\ Yuhelson $^{3}$, Prasetya ${ }^{1,2, *}$ \\ ${ }^{1}$ Faculty of Mathematics, Natural Sciences and Health, Universitas Muhammadiyah Riau, Indonesia \\ ${ }^{2}$ Departement of Chemistry, Faculty of Mathematics and Natural Sciences, Universitas Riau, Indonesia \\ ${ }^{3}$ Faculty of Engineering, Universitas Muhammadiyah Riau, Indonesia \\ Correspondense Email: prasetya@umri.ac.id
}

\begin{abstract}
Biodiesel is an alternative fuel for diesel engines produced by a transesterification reaction between vegetable oils or animal fats containing triglycerides and alcohol, one of which is methanol. The use of homogeneous base catalysts in the synthesis of biodiesel still poses a problem for the environment because it is difficult to separate, therefore, researchers use variations of heterogeneous base catalysts. The synthesis of biodiesel from used cooking oil was carried out through a transesterification reaction with technical methanol with a catalyst of $\mathrm{CaO}$ impregnated Bentonite, K-Bentonite and Bentonite using the reflux method at $65^{\circ} \mathrm{C}$ for 2 hours. The ratio of the volume of oil, methanol, and catalyst used is 5:1:1\%-w oil. Based on the research that has been done, the yield of each catalyst is $84.85 \%$ bentonite, $84.24 \%$ K-bentonite and $89.27 \%$ K-bentonite-CaO. The characteristics of biodiesel obtained from each of these catalysts such as calorific value and density have met the quality requirements of the Indonesian National Standard (SNI 7182-2012), except for the acid number and kinematic viscosity which still exceed the quality requirements of SNI 7182-2012.
\end{abstract}

Key words: Biodiesel, Bentonite, Calcium oxide, Cooking oil.

\section{ABSTRAK}

Biodiesel adalah bahan bakar alternatif mesin diesel yang dihasilkan reaksi transesterifikasi antara minyak nabati atau lemak hewani yang mengandung trigliserida dengan alkohol, salah satunya metanol. Penggunaan katalis basa homogen dalam sintesis biodiesel masih menimbulkan masalah bagi lingkungan karena sulit dipisahkan, oleh karena itu, peneliti menggunakan variasi katalis basa heterogen. Sintesis biodiesel dari minyak jelantah dilakukan melalui reaksi transesterifikasi dengan metanol teknis dengan katalis Bentonit, K-Bentonit dan K-Bentonit terimpregnasi CaO menggunakan metode refluks pada suhu $65^{\circ} \mathrm{C}$ selama 2 jam. Perbandingan volume minyak, methanol, dan katalis yang digunakan adalah 5:1:1\%-b minyak. Berdasarkan penelitian yang telah dilakukan, diperoleh rendemen dari masing-masing katalis yaitu Bentonit 84,85\%, K-Bentonit 84,24\% dan KBentonit-CaO 89,27\%. Karakteristik biodiesel yang diperoleh dari masing-masing katalis tersebut seperti nilai kalor dan massa jenis telah memenuhi syarat mutu Standar Nasional Indonesia (SNI 7182-2012), kecuali angka asam dan viskositas kinematik yang masih melebihi syarat mutu SNI 7182-2012.

Kata kunci : Biodiesel, Bentonit, Kalsium oksida, Minyak jelantah.

Received: November 2021, Accepted : November 2021 - Jurnal Photon Vol.12 No.1

DOI : https://doi.org/10.37859/jp.v12i1.3312

PHOTON is licensed under a Creative Commons Attribution-ShareAlike 4.0 International License 


\section{Introduction}

Dalam satu dekade terakhir, konsumsi energi primer Indonesia telah naik 50 persen. Indonesia sampai saat ini masih bergantung pada bahan bakar fosil. Banyaknya permintaan untuk bahan bakar fosil meningkat signifikan. Hal ini telah mendorong peneliti untuk terus mencari sumber energi alternatif yang efisien dan efektif (Tamilselvan et al., 2017). Salah satu energi alternatif yang dapat dikembangkan adalah biodiesel. Biodiesel dipilih sebagai salah satu bahan bakar alternatif dikarenakan tidak adanya kandungan sulfur dan aromatik, biodegradibilitas, dan emisi gas rumah kaca lebih rendah 30-71\%. Kendala yang dihadapi dalam penggunaan biodiesel adalah harganya yang lebih mahal dibandingkan bahan bakar solar (Kartika et al., 2012). Pilihan alternatif untuk mengatasi tingginya harga biodiesel tersebut adalah dengan memanfaatkan minyak jelantah atau yang biasa dikenal dengan minyak goreng bekas. Katalis yang digunakan pada pembuatan biodiesel ini didasarkan pada katalis heterogen dikarenakan ramah lingkungan, tidak bersifat korosif, mudah dipisahkan dari produk dengan cara filtrasi, serta dapat digunakan berulang kali dalam jangka waktu yang lama (Uprety et al., 2016). Sintesis biodiesel dari minyak jelantah ini menggunakan katalis bentonit dari lempung dan $\mathrm{CaO}$ dari $\mathrm{CaCO}_{3}$.

\section{The Methods}

\section{Preparasi Minyak Jelantah}

Minyak jelantah yang digunakan berasal dari limbah minyak jelantah yang diperoleh dari industri pembuatan kerupuk dan tempat penjualan ayam goreng di Marpoyan serta limbah minyak jelantah dari cafe di daerah Senapelan dikumpulkan dan disaring terlebih dahulu dengan kertas saring untuk menghilang endapan maupun zat sisa lainnya.

\section{Penentuan asam lemak bebas (ALB) minyak jelantah (SNI 01-3555-1998)}

Sebanyak 20 gram minyak jelantah ditimbang dan dimasukkan ke dalam erlenmeyer $250 \mathrm{ml}$. Selanjutnya ditambahkan $50 \mathrm{ml}$ Alkohol 96\%. Larutan selanjutnya dipanaskan selama \pm 10 menit dalam penangas air sambil teraduk. Lalu ditambahkan 2-3 tetes indikator PP dan kemudian diaduk sampai homogen. Larutan ini kemudian dititrasi dengan larutan $\mathrm{KOH} 0,1 \mathrm{~N}$ (standar sekunder) sampai timbul warna merah muda (pink). Sedangkan larutan standar sekunder $(\mathrm{KOH})$ dititrasi dengan standar primer asam oksalat.

\section{Persiapan Katalis}

\section{Persiapan sampel bentonit}

Lempung bentonit diayak kemudian dicuci selanjutnya disaring dengan penyaringan vakum dan dikeringkan dalam oven. Lempung bentonit kering diperoleh kemudian diayak menggunakan ayakan 100 mesh.

Received: November 2021, Accepted : November 2021 - Jurnal Photon Vol.12 No.1

DOI : https://doi.org/10.37859/jp.v12i1.3312

PHOTON is licensed under a Creative Commons Attribution-ShareAlike 4.0 International License 


\section{http://ejurnal.umri.ac.id/index.php/}

\section{Persiapan sampel CaO}

Lakukan pengapuran $\mathrm{CaCO}_{3}$ dalam furnace selama jam pada suhu $950{ }^{\circ} \mathrm{C}$ untuk mendapatkan $\mathrm{CaO}$, kemudian dinginkan dalam desikator, haluskan dan ayak menggunakan mesh 100 (Mahesh et al., 2015).

\section{Preparasi lempung K-Bentonit}

Sekitar 20 gram bentonit ke dalam $350 \mathrm{~mL}$ larutan $\mathrm{KCl} 1 \mathrm{M}$. Suspensi diaduk dengan pengaduk magnetik selama 24 jam pada suhu $70^{\circ} \mathrm{C}$. Larutan kalium klorida tersebut setiap hari diganti dengan yang baru selama 1 minggu. Sedimen dipisahkan dari suspensinya secara dekantasi. Sedimen dicuci dengan akuades untuk menghilangkan sisa ion klorida kemudian cucian diuji dengan menggunakan larutan perak nitrat $1 \mathrm{M}$. Jika tes menunjukkan hasil negatif terhadap perak nitrat, artinya tidak terbentuk endapan putih $\mathrm{AgCl}$ maka proses pencucian dihentikan. Bentonit yang sudah dicuci selanjutnya dikeringkan pada suhu $100^{\circ} \mathrm{C}$. Bentonit kering ini kemudian diberi kode K-Bentonit.

\section{Memodifikasi K-Bentonit menjadi K-Bentonit terimpregnasi CaO}

Pemasukan gugus $\mathrm{CaO}$ ke dalam molekul lempung K-bentonit dengan cara impregnasi (metode refluks dan keramik) dengan perbandingan antara $\mathrm{CaO}$ dengan $\mathrm{K}$-bentonit 5:5. Setelah impregnasi katalis yang dihasilkan dikeringkan pada suhu $150^{\circ} \mathrm{C}$ selama 30 menit dan kalsinasi pada suhu $950^{\circ} \mathrm{C}$ selama 3 jam.

\section{Sintesis Biodiesel}

Pembuatan biodiesel dilakukan dengan cara minyak jelantah ditransesterifikasi dengan methanol meggunakan katalis Bentonit, K-Bentonit,dan K-Bentonit terimpregnasi $\mathrm{CaO}$ yang telah dipreparasi dan diimpregasi sebelumya. Perbandingan volume minyak jelantah : metanol : katalis yang dilakukan dalam penelitian ini adalah sebesar $5: 1: 1 \%$-(b minyak). Proses transesterifikasi dilakukan dengan menghomogenkan katalis dan metanol dalam labulehertiga selama \pm 30 menit. Setelah homogen, ditambahkan minyak jelantah kedalam labu leher tiga dan direfluk pada suhu $65^{\circ} \mathrm{C}$ selama 3 jam. Setelah 3 jam, campuran didiamkan selama 1 malam kemudian campuran disaring dan dimasukkan dalam corong pisah untuk memisahkan katalis dari campuran biodiesel dan gliserol (Prasetya et al., 2016).

\section{Pencucian biodiesel}

Kedalam corong pisah dimasukkan air hangat dan biodiesel dengan perbandingan volume 1:1, diaduk dengan pengadukan selama 5 menit, biodiesel dengan air akan membentuk campuran berwarna putih. Campuran ini dimasukkan kedalam corong pisah, dibiarkan beberapa menit sehingga terjadi dua lapisan, yaitu fase air (campuran putih) dan fase biodiesel (bening). Air dikeluarkan dari corong pisah, selanjutnya biodiesel yang diperoleh dipanaskan lagi pada ushu $105^{\circ} \mathrm{C}$ untuk menghilangkan sisa-sisa air biodiesel.

Received: November 2021, Accepted : November 2021 - Jurnal Photon Vol.12 No.1

DOI : https://doi.org/10.37859/jp.v12i1.3312

PHOTON is licensed under a Creative Commons Attribution-ShareAlike 4.0 International License 
http://ejurnal.umri.ac.id/index.php/

Uji kualitas biodiesel dengan karakteristik sesuai SNI biodiesel (SNI 7182-2012)

\section{Penentuan bilangan asam}

Ditimbang 19-21 \pm 0.05 gram biodiesel dan dimasukkan kedalam erlenmeyer $250 \mathrm{~mL}$. Ditambah $100 \mathrm{~mL}$ alkohol netral 96\%. Dipanaskan selama 10 menit dalam penangas air sambil diaduk. Dalam keadaan teraduk kuat,larutan ini dititrasi dengan larutah $\mathrm{KOH} 0.1 \mathrm{~N}$ (distandardisasi dengan standar primer PHP) dengan indikator pp sampai terbentuk warna merah muda (pink) serta volume $\mathrm{KOH}$ terpakai $(\mathrm{V} \mathrm{mL})$ dicatat.

\section{Penentuan berat jenis}

Piknometer yang bersih dan kering ditentukan massanya, lalu diisi dengan biodiesel. Kemudian ditutup hingga ada biodiesel yang keluar dari lubang tutup piknometer. Piknometer beserta isinya ditimbang. Selanjutnya piknometer dibersihkan dan dikeringkan. Lalu dihitung massa jenis biodiesel.

\section{Penentuan viskositas}

Alat viskositas dibersihkan dengan aseton. Biodiesel dimasukkan kedalam viskometer, dan viskometer ini diletakkan didalam waterbath dengan suhu $40^{\circ} \mathrm{C}$. Biodiesel dipompa hingga ke batas $\mathrm{X}$, catat waktu penurunan biodiesel dari X-Y (tx-ty).

\section{Nilai Kalor}

Nilai kalor diukur dengan bomb kalorimeter, sebelum dipakai bomb dikalibrasi (standardisasi) dengan asam benzoat. Kalorimeter ini membakar bahan bakar secara adiabatis dengan isolator sempurna. Kenaikan temperatur ini untuk menghitung kalor yang dihasilkan (Haryono et al., 2017).

\section{Result and Discussion}

\section{Karakteristik minyak jelantah}

Pengujian kadar asam lemak bebas (ALB) dilakukan untuk mengetahui kadar asam lemak bebas yang terdapat minyak jelantah. Semakin kecil kadar ALB dalam minyak jelantah maka kualitas dari minyak tersebut masih baik (Siswani et al., 2012). Tabel 1 menampilkan karakteristik asam lemak bebas minyak jelantah. Kadar ALB pada minyak jelantah yang digunakan sebesar 1,0014\%. Menurut Mahreni et al (2010) minyak kelapa sawit yang baik untuk sintesis biodiesel mempunyai kandungan ALB $<2 \%$. Dari hasil tersebut minyak jelantah dapat dijadikan sebagai bahan baku sintesis biodiesel.

Tabel 1. Asam Lemak Bebas Minyak Jelantah

\begin{tabular}{cccc} 
Sampel & $\begin{array}{c}\text { Asam Lemak Bebas } \\
(\mathbf{A L B})(\boldsymbol{\%})\end{array}$ & $\begin{array}{c}\text { Massa Jenis } \\
\left(\mathbf{K g} / \mathbf{m}^{3}\right)\end{array}$ & $\begin{array}{c}\text { Kadar Air } \\
(\boldsymbol{\%})\end{array}$ \\
\hline Minyak Jelantah & 1,0014 & 0,8570 & 0,1044 \\
\hline
\end{tabular}

Received: November 2021, Accepted : November 2021 - Jurnal Photon Vol.12 No.1

DOI : https://doi.org/10.37859/jp.v12i1.3312

PHOTON is licensed under a Creative Commons Attribution-ShareAlike 4.0 International License 


\section{http://ejurnal.umri.ac.id/index.php/}

\section{Karakteristik Biodiesel}

\section{Data rendemen}

Tabel 2 menampilkan karakteristik bidiesel hasil disintesis. Sintesis biodiesel menggunakan katalis K-Bentonit dengan suhu $65{ }^{\circ} \mathrm{C}$ selama 3 jam menghasilkan rendemen tinggi sebesar 86,06\%, sedangkan pada katalis $\mathrm{K}$ Bentonit- $\mathrm{CaO}$ menghasilkan rendemen terendah sebesar 64,85\%. Hal ini dikarenakan suhu pemanasan optimum metanol telah tercapai maka hasil berat biodiesel yang didapatkan semakin menurun. Pada penelitian Mawarni et al (2018) Saat suhu proses $50{ }^{\circ} \mathrm{C}$ bahan baku dari minyak jelantah sudah menerima panas yang maksimal untuk bereaksi dibanding dengan suhu lainnya.

Tabel 2. Karakteristik Biodiesel

\begin{tabular}{cccccc}
\hline Katalis & $\begin{array}{c}\text { Angka Asam } \\
(\mathbf{m g K O H} / \mathbf{g r} \\
\text { Biodiesel })\end{array}$ & $\begin{array}{c}\text { Massa } \\
\text { Jenis } \\
\left(\mathbf{K g} / \mathbf{m}^{\mathbf{3}}\right)\end{array}$ & $\begin{array}{c}\text { Viskositas } \\
(\mathbf{c S t})\end{array}$ & $\begin{array}{c}\text { Nilai Kalor } \\
(\mathbf{C a l} / \mathbf{g})\end{array}$ & $\begin{array}{c}\text { Rendemen } \\
(\boldsymbol{\%})\end{array}$ \\
\hline Bentonit & 3,0238 & 887,9 & 28,2460 & 9315,5 & 84,85 \\
K-Bentonit & 3,1615 & 889,8 & 28,3809 & 9348,0 & 86,06 \\
K-Bentonit-CaO & 1,0083 & 891,6 & 37,8470 & 9338,2 & 64,85 \\
\hline
\end{tabular}

\section{Penentuan bilangan asam}

Hasil angka asam secara berturut-turut dari sintesis biodiesel yang menggunakan katalis Bentonit, K-bentonit dn K-bentonit-CaO sebesar 3.02, 3.16 dan $1.008 \mathrm{mg}-\mathrm{KOH} / \mathrm{g}$. Angka asam pada hasil biodiesel meningkat dibandingkan dengan angka asam bahan baku minyak jelantah sebesar 1,0014\%.

Nilai angka asam biodiesel dari masing-masing katalis lebih tinggi dari SNI 7182-2012 maksimal 0.6 mgKOH/g. Menurut Haryanto et al (2015) tingginya bilangan asam disebabkan oleh penggunaan metanol teknis (70\%) sebagai pereaksi saat sintesis biodiesel sehingga mengakibatkan reaksi kurang sempurna. Angka asam yang tinggi merupakan indikator bahwa biodiesel masih mengandung asam lemak bebas. Bidiesel seperti ini tidak dapat digunakan pada mesin diesel karena mengakibatkan keausan mesin.

\section{Penentuan massa jenis}

Biodiesel yang disintesis dengan menggunakan katalis Bentonit memiliki massa jenis sebesar $887.95 \mathrm{Kg} / \mathrm{m}^{3}, \mathrm{~K}-$ bentonit sebesar $889.89 \mathrm{Kg} / \mathrm{m}^{3}$ sedangkan massa jenis biodiesel yang menggunakan katalis K-bentonit-CaO sebesar $891.62 \mathrm{Kg} / \mathrm{m}^{3}$. Nilai yang diperoleh tersebut memenuhi standar mutu biodiesel menurut SNI $7182-2012$ yaitu berkisar $850-890 \mathrm{Kg} / \mathrm{m}^{3}$. Apabila biodiesel menghasilkan massa jenis yang melebihi standar akan menyebabkan reaksi pembakaran tidak sempurna sehingga dapat meningkatkan emisi dan keausan mesin.

Received: November 2021, Accepted : November 2021 - Jurnal Photon Vol.12 No.1

DOI : https://doi.org/10.37859/jp.v12i1.3312

PHOTON is licensed under a Creative Commons Attribution-ShareAlike 4.0 International License 


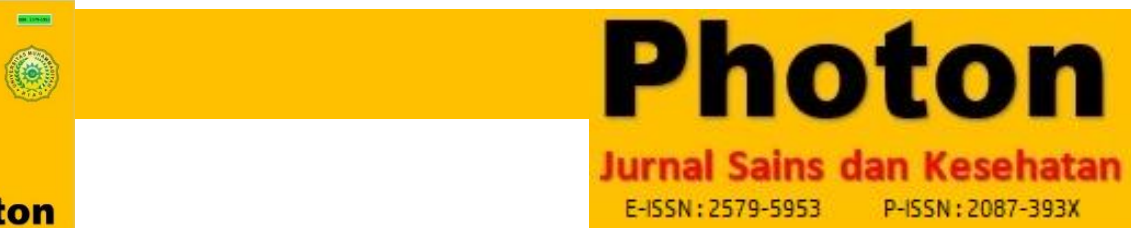

\section{http://ejurnal.umri.ac.id/index.php/}

\section{Penentuan viskositas kinematik}

Hasil dari pengujian viskositas meggunakan viskometer Ostwald dengan katalis Bentonit, K-bentonit dan Kbentonit-CaO sebesar 28.264, 28.3809, dan $37.847 \mathrm{cSt} / \mathrm{s}$ sedangkan menurut standar SNI 7182-2012 nilai viskositas berkisar antara 2.3-6.0 cSt/s. Hasil dari masing-masing katalis tersebut tidak memenuhi standar. Menurut Nurfadillah (2011), viskositas yang tinggi disebabkan pada saat proses transesterifikasi, dimana asam lemak bereaksi dengan katalis $\mathrm{NaOH}$ dan membentuk sabun dan viskositas yang tinggi disebabkan oleh reaksi transesterifikasi yang belum berjalan sempurna maka masih terdapat trigliserida yang belum terkonversi menjadi metil ester. Viskositas yang terlalu tinggi akan menyebabkan asap yang kotor karena bahan bakar lambat mengalir dan lebih sulit teratomisasi.

\section{Penentuan Nilai Kalor}

Berdasarkan uji yang dilakukan diperoleh nilai kalor pembakaran untuk biodiesel menggunakan katalis Bentonit, K-Bentonit, dan K-Bentonit-CaO sebagaimana hasilnya sebesar 9315.5, 9348 dan, $9338.2 \mathrm{kal} / \mathrm{g}$. Dari hasil yang diperoleh, biodiesel tersebut hasilnya tidak jauh berbeda dari hasil penelitian sebelumnya. Menurut Sukmana $e t$ al (2011) Kalor dalam biodiesel dipengaruhi oleh senyawa penyusun yang tergantung pada bahan dasarnya dan densitas biodiesel, makin tinggi densitas bahan bakar maka makin rendah nilai kalor yang diperolehnya.

\section{Conclusion}

Penelitian ini membuktikan Bentonit, K-Bentonit dan K-Bentonit-CaO dapat digunakan sebagai katalis untuk mensintesis minyak jelantah dengan metanol menjadi biodiesel dengan rendemen secara berturut-turut sebesar 84.85, 84.24, dan 89.27\%. Karakteristik sifat fisik dan kimia biodiesel massa jenis dan nilai kalor yang disintesis menggunakan katalis Bentonit, K-Bentonit, dan K-bentonit-CaO telah memenuhi standar SNI 7182-2012, kecuali angka asam dan viskositas.

\section{Acknowledgement}

Penulis mengucapkan terima kasih atas pendanaan Deputi Penguatan Riset dan Pengembangan Kementerian Riset dan Teknologi/Badan Riset dan Inovasi Nasional (BRIN) melalui LLDIKTI Wilayah X, Kementerian Pendidikan, Kebudayaan, Riset dan Teknologi (Mendikbudristek), dan Lembaga Penelitian Pengabdian kepada Masyarakat Universitas Muhammadiyah Riau (LPPM-UMRI).

\section{References}

Badan Standardisasi Nasional. (1998). SNI 01-3555-1998. Cara uji minyak dan lemak.

Badan Standardisasi Nasional. (1998). SNI 7182-2012. Karakteristik kualitas Biodiesel.

Haryanto, A., Silviana, U., Triyono, S., \& Prabawa, S. (2015). Produksi biodiesel dari transesterifikasi minyak jelantah dengan bantuan gelombang mikro: pengaruh intesitas daya dan waktu reaksi terhadap rendemen dan karakteristik biodiesel. Agritech, 35(2), 234-240.

Haryono, E., Dimas, R., Witjonarko, E., Teknik, J., Kapal, P., Perkapalan, P., \& Surabaya, N. (2017). Analisa Unjuk Kerja Mesin Diesel Kapal Dua Langkah ( Two Stroke Marine Diesel Engine ) Berbahan Bakar Campuran Minyak Solar ( Hsd ) Dan Biodiesel Minyak Jelantah Pada Beban Simulator Full Load. Jurnal Inovtek Polbeng, 7(2).

Kartika, D., \& Widyaningsih, S. (2012). Konsentrasi Katalis dan Suhu Optimum pada Reaksi Esterifikasi menggunakan Katalis Zeolit Alam Aktif ( ZAH ) dalam Pembuatan Biodiesel dari Minyak Jelantah. Jurnal Natur Indonesia, 14(3), 219-226.

Received: November 2021, Accepted : November 2021 - Jurnal Photon Vol.12 No.1

DOI : https://doi.org/10.37859/jp.v12i1.3312

PHOTON is licensed under a Creative Commons Attribution-ShareAlike 4.0 International License 


\section{http://eiurnal.umri.ac.id/index.php/}

Mahesh, S. E., Ramanathan, A., Begum, K. M. M. S., \& Narayanan, A. (2015). Biodiesel production from waste cooking oil using $\mathrm{KBr}$ impregnated $\mathrm{CaO}$ as catalyst. Energy Conversion and Management, 91, 442-450.

Mahreni, \& Setyoningrum, T. M. (2010). Produksi Biodisel dari Minyak Jelantah Menggunakan Katalis Asam padat ( Nafion / SiO 2 ). Jurnal Eksergi, X, 52-57.

Mawarni, D. I., Tinggi, S., Ronggolawe, T., Suryanto, H., Tinggi, S., \& Ronggolawe, T. (2018). pengaruh suhu pengadukan terhadap yield biodiesel dari. Jurnal SIMETRIS, 9(1), 49-54.

Nurfadillah. (2011). Pemanfaatan dan uji kualitas biodiesel dari minyak jelantah. Skripsi.Program Studi Kimia fakultas Sains da Teknologi: Universitas Islam Negeri Alauddin.

Prasetya, Yuhelson, Fauzi, M. ., \& Triasih, P. (2016). Penggunaan lempung bentonit sebagai katalis heterogen yang ramah lingkungan dibandingkan katalis homogen untuk produksi biodiesel dari minyak sawit bekas penggorengan. Prosiding Seminar nasional “Pelestarian Lngkungan Dan Mitigasi Bencana,” 11-16.

Siswani, E. D., Kristianingrum, S., \& Suwardi. (2012). Sintesis dan karakterisasi biodiesel dari minyak jelantah pada berbagai waktu dan suhu. Prosiding Seminar Nasional Penelitian, Pendidikan Dan Penerapan, 103112.

Sukmana, N. C., \& S, E. P. (2011). Kalor Biodiesel Hasil Esterifikasi Dengan Katalis Asam Sitrat Dan Transesterifikasi Dengan Katalis Kalium Hidroksida Minyak Biji Nyamplung (Calophyllum inophyllum). Prosiding Tugas Akhir Semester Genap, 1.

Tamilselvan, P., Nallusamy, N., \& Rajkumar, S. (2017). A comprehensive review on performance, combustion and emission characteristics of biodiesel fuelled diesel engines. Renewable and Sustainable Energy Reviews, 79(April), 1134-1159.

Uprety, B. K., Chaiwong, W., Ewelike, C., \& Rakshit, S. K. (2016). Biodiesel production using heterogeneous catalysts including wood ash and the importance of enhancing byproduct glycerol purity. Energy Conversion and Management, 115, 191-199.

Received: November 2021, Accepted : November 2021 - Jurnal Photon Vol.12 No.1

DOI : https://doi.org/10.37859/jp.v12i1.3312

PHOTON is licensed under a Creative Commons Attribution-ShareAlike 4.0 International License 